\title{
American fast food industry making millions for the medical industry
}

\section{Conceptual}

This may sound strange to many but have you ever wondered how the fast food industry, pharmaceutical and healthcare industry may be working together to create markets that feed upon each other?

Few will argue that most 'fast food' places do not serve the most healthy or nutritious fare. The high fat, high salt and high sugar content of most fast food and processed/packaged food in general, is viewed as not the healthiest things you can eat. Yet, most people constantly indulge in them, while ignoring their expanding waste lines, ever rising blood pressure and climbing glycemic blood glucose.

Many to most Americans are on some form of medication to treat health conditions typically brought on by lifestyle choices. Choosing fast food over a meal prepared at home is one of those lifestyle choices. Picking up the phone and ordering pizza instead of preparing a more nutritious and balanced meal at home is all too often the case; especially with younger single people. It's just easier!

The Fast Food Market business is rapidly expanding outside the USA. You can walk down a street in Hong Kong and see McDonalds, Kentucky Fried Chicken and other fast food establishments popping up. In almost every country on the Planet, you see American Fast Food chains selling their products.

\section{Health industry profits from fast food}

The rise in obesity, diabetes two, heart disease, high blood pressure, arterial disease, cancers, autism in children, ADHD in adults and children and more, ALL seem to be directly correlated to the rise in Fast Food and processed food consumption.

The pharmaceutical industry has blossomed as cases of heart disease, cancer and Type II Diabetes have continued to rise. More drugs hit the market and all you need to do is watch TV to see the plethora of new drugs. Then there are debilitating side effects of these drugs, listed by fast talking admen, but ignored by the viewer, that generate more prescriptions to treat the side effects of the drugs previously prescribed!

The ever-increasing consumption of drugs, increased medical treatment procedures to treat (but never seem to CURE) diseases and health conditions are on an ever-increasing rise. Billions upon Billions of dollars are spent to fund research that never seems to produce a cure, just a plethora of new treatments for diseases; many of which are caused by a 'fast food lifestyle' and poor overall nutrition.

Let's face it, Americans are being treated to Death and now it has spread to almost every country on the Planet. All the while, the pharmaceutical industry and medical establishments feed off the debilitating disease and side effects caused by the consumption of fast food.

\section{Always follow the money trail}

Fast Food Companies rake in massive profits by producing and

\author{
Volume 6 Issue I - 2017
}

\section{Skip Stein}

Plant Based Lifestyle Consultant, Whole Foods 4 Healthy Living, USA

Correspondence: Skip Stein, Plant Based Lifestyle Consultant, Chief Operating Officer, Whole Foods 4 Healthy Living, Orlando, USA, Tel 40768368I6, Email SkipStein@newtimers.org

Received: January 10, 2017 | Published: January 27, 2017

serving cheap products that are addictive to naive populations. The high fat, salt, sugar components have been shown to be as addictive as some narcotics. In many cases, the content of the fast food include products that are subsidized by the government. Farm subsidies for GMO production of corn, soy and animal production make it cheap for fast food companies to get raw materials to deliver products inexpensively to the consumer.

The drug companies churn out low cost to produce but high consumer cost drugs to treat the diseases that fast food consumers contract; either directly or indirectly caused by consumption of poor nutrition fed to them by fast food conglomerates.

The Fast Food and Pharmaceutical industries work with the medical industry as a team to profit from rampant diseases. Poorly educated health care professionals (yes Doctors!) have little to no clue about nutrition and are often disease ridden themselves; often from consuming the same fast food their patients consume.

All of these corporations spend Billions of dollars paying high powered political lobbyists in Washington D.C. and State Houses to convince politicians (who themselves are fast food consumers and patients) to ignore the most obvious deleterious health impacts caused by lousy nutrition delivered by fast food chains.

\section{What is the real CURE?}

The Real Cure for this ever-increasing cycle of disease/treatment cycle is to DIY. Yes, we must just Do It Ourselves! There is NO time to waste trying to convince the massive moneyed interests to change, they will NEVER do it. We The People MUST realize that consuming these fast foods, packaged processed 'foodstuffs' are killing US. Do NOT commit this slow suicide but decide to Live and Prosper.

It really isn't that difficult. Many people are demanding healthier food, building information networks that have shown that there IS a better and healthier way to live and Enjoy Natural Whole Foods! 
There are many healthier 'faster food' establishments, restaurants that are now realizing that their previous clientele were dying off and to continue in business, they need to keep the customers healthy enough to keep coming back.

It is ALL about Lifestyle and Food choices. It is not that difficult to do either! You will save Time and MONEY by getting healthier; you will have more energy and look/feel better. You may lose that extra poundage and loose a few inches around that bulging waistline.

The KEY is to focus more on Whole Plant Foods for a Healthier Lifestyle! We at Whole Foods 4 Healthy Living can help teach you how to prepare meals that are Plant Based, DELICOUS and Nutritious. We can help you adjust your Lifestyle to include healthier activities. With your increased energy levels, you will Want to get up and MOVE.
Just think how great it will be to seldom get sick, feel great every day, sleep better, look younger and BE YOUNGER inside and out! It is SO EASY and you can SAVE MONEY all at the same time. Fewer doctor visits and co-pays. Few to NO DRUGS and NO Side Effects from undesired drug interactions. Just good health, vitality and long life!

You have got SO much to gain and all you have to do is Eat Delicious Whole FOOD!

\section{Acknowledgements}

None.

\section{Conflict of interest}

Author declares that there is no conflict of interest. 